\title{
PERAN AUDIT INTERNAL DALAM MENDUKUNG GOOD CORPORATE GOVERNANCE PADA PT. PELABUHAN INDONESIA IV (PERSERO) MAKASSAR
}

\author{
Andi Rustam ${ }^{1}$ Faidul Adzim² ${ }^{2}$ Aulia Meilani ${ }^{3}$ \\ ${ }^{1,2}$ Universitas Muhammadiyah Makassar \\ e-mail: andirust99@gmail.com
}

\begin{abstract}
Research aims to determine if an adequate internal audt has a role in supporting good corporate governance effective at PT. Pelabuhan Indonesia IV (Persero) Makassar. This study was conducted using case study method with analytical descriptive method, while the population in this research is all employees who are in the Internal control unit and Corporate Secretary section. Research Data is obtained using questionnaires. Based on the results of research conducted by the authors showed that adequate internal audit has a role in supporting good corporate governance effective at PT. Pelabuhan Indonesia IV (Persero) which means between internal audit in Implementation of GCG showing positive relationship
\end{abstract}

Keywords: Internal Audit, Good Corporate Governance

\begin{abstract}
Abstrak
Penelitian ini bertujuan untuk mengetahui apakah audt internal yang memadai mempunyai peranan dalam mendukung good corporate governance yang efektif pada PT. Pelabuhan Indonesia IV (Persero) Makassar. Penelitian ini dilakukan dengan menggunakan metode studi kasus dengan metode deskriptif analitis, sedangkan populasi dalam penelitian ini adalah seluruh pegawai yang berada pada bagian Satuan Pengawasan Internal dan Sekretaris Perusahaan. Data penelitian diperoleh dengan menggunakan kuesioner. Berdasarkan hasil penelitian yang dilakukan oleh penulis menunjukkan bahwa audit internal yang memadai mempunyai peranan dalam mendukung good corporate governance yang efektif pada PT. Pelabuhan Indonesia IV (Persero) yang berarti antara audit internal dalam penerapan GCG menunjukka hubungan yang positif
\end{abstract}

Kata Kunci: Audit Internal, Good Corporate Governance 


\section{PENDAHULUAN}

Perkembangan globalisasi dunia bisnis memicu para pelaku bisnis dan ekonomi untuk melakukan berbagai tindakan agar bisnisnya tetap bertahan di dunia bisnis dan semakin meningkatnya operasi dalam perusahaan, manajemen puncak tidak memiliki komunikasi yang cukup dengan berbagai operasi yang ada untuk menilai keefektifan kinerja sehingga menjadi titik kelemahan dalam perusahaan. Mengatasi hal ini salah satu fungsi yang harus diberdayakan secara konsisten adalah fungsi pengawasan yang dapat memicu terlaksananya pengendalian risiko manajemen sistem pengendalian dan penataan manajemen yang sehat untuk mendorong kesinambungan dan kelangsungan hidup usaha. Dalam melaksanakan pengendalian dapat dilakukan secara langsung oleh anggota perusahaan dan dapat pula dilakukan oleh suatu departemen auditinternal. Pihak manajemen dapat membentuk suatu departemen audit intern yang diberi wewenang untuk melakukan pengawasan dan penilaian terhadappengendalian intern perusahaan. Struktur pengendalian intern dimaksudkan untuk melindungi harta milik perusahaan, menilai kecermatan dan keandalan dataakuntansi, meningkatkan efisiensi usaha dan mendorong ditaatinya kebijaksanaan manajemen yang telah digariskan. Audit internal modern menyediakan jasa-jasa yang mencakup pemeriksaan dan penilaian kontrol, kerja, risiko dan tata kelola (governance) perusahaan publik maupun privat.

Audit internal membantu organisasi untuk mencapai tujuannya, melaluisuatu pendekatan yang sistematis dan teratur untuk mengevaluasi dan meningkatkan efektivitas pengelolaan risiko, pengendalian dan prosesgovernance. Peran audit internal akan semakin dapat diandalkan dalam mengembangkan dan menjaga efektifitas sistem pengendalian internal, pengelolaan risiko dan Good Corporate Governance guna menopang terwujudnya suatu perusahaan yang sehat. Suatu mekanisme dalam sistem pengendalian internal merupakan salah satu sarana utama untuk dapat memastikan bahwa pengelolaan perusahaan telah dilaksanakan sesuai dengan prinsip-prinsip Good Corporate Governance. Perubahan yang terjadi pada lingkungan bisnis dan era globalisasi menuntut dikembangkanya suatu sistem dan paragdima baru dalam pengelolaan bisnis dan industri.

Good Corporate Governance (GCG) atau yang lebih umum dikenal dengan tata kelola perusahaan yang baik muncul sebagai suatu pilihan yang bukan saja menjadi formalitas namun suatu sistem nilai dan best practices yang sangat fundamental bagi peningkatan nilai perusahaan.

\section{TINJAUAN PUSTAKA}

\section{Audit Internal}

Menurut Amin Wijaya Tunggal (2005:3) "Audit Internal adalah pekerjaan penilaian yang bebas (independent) di dalam suatu organisasi meninjau kegiatankegiatan perusahaan guna memenuhi kebutuhan pimpinan.

\section{Tujuan Audit Internal}

Tujuan utama audit internal adalah untuk membantu anggota organisasi dalam melaksanakan tanggung jawabnya secara efektif. Oleh karena itu audit internal dilengkapi dengan analisis, penilaian, rekomendasi, nasehat, dan informasi mengenai tujuan aktivitas. Tujuan audit meliputi promosi pengendalian yang efektif dengan biaya yang wajar.Tujuan pemeriksaan yang dilakukan oleh internal auditor adalah untuk membantu semua pimpinan perusahaan (manajemen) dalam melaksanakan tanggung jawabnya dengan memberikan analisis, penilaian, saran, dan komentar mengenai kegiatan yang diperiksanya

\section{Good Corporate Governance (GCG)}

Good Corporate governance adalah suatu sistem yang ada pada suatu organisasi yang memiliki tujuan untuk mencapai kinerja organisasi semaksimal mungkin dengan caracara yang tidak merugikan stakeholder organisasi tersebut. (Partolo, 2007). Prinsip GCG terdiri dari Transparansi (transparency), 
Akuntabilitas (accountability), Responsibilitas (responsibility), dan Kewajaran dan Kesetaraan (fairness). Penerapan GCG pada masing-masing negara sangat ditentukan oleh sistem ekonomi, hukum, struktur kepemilikan, sosial dan budaya. Berkaitan dengan sistem ekonomi, GCG tidak dapat dilaksanakan secara parsial, namun harus dilaksanakan bersama. Perkembangan pasar modal dan sektor keuangan, terutama sektor perbankan sangat memengaruhi efektivitas penerapan GCG.

\section{METODE}

\section{Pendekatan Penelitian}

Pendekatan yang digunakan dalam penelitian ini adalah pendekatan kuantitatif dengan ilmiah yaitu berfikit untuk memecahkan masalah secara sistematis, empiris, dan terkontrol yang dengan angka-angka. Objek penelitian ini adalah melakukan penelitian pada PT Pelabuhan Indonesia IV (Persero) Makassar yang berlokasi di Jl. Soekarno Hatta No. 1 Makassar. Adapun jenis data yang digunakan dalam penelitian ini adalah data kualitatif dan kuantitatof, sedangkan Sumber data yang diperoleh dalam penelitian ini adalah sumber primer dan sekunder.

\section{Metode Analisis Data}

Adapun metode analisis data yang digunakan dengan Pengujian Data (Uji Validitas dan Uji Reliabilitas), dan Uji Statistik. Uji Statistik dengan koefisien korelasi peason digunakan untuk mengukur keeratan hubungan antara dua variabel yang datanya berbentuk data interval atau rasio (Hasan, 2002: 235). Penelitian ini menggunakan skala likert karena mempelajari bagaimana respon berbeda dari satu orang ke orang lain dan bagaimana respon berbeda antara berbagai objek. Skala likert diperlakukan sebagai skala interval Koefisien korelasi pearson dapat dihitung dengan rumus sebagai berikut (Hasan, 2002,235):

$$
\mathrm{r}=\frac{n \Sigma X Y-\Sigma X \Sigma Y}{\sqrt{\left(n \Sigma^{2}-(\Sigma X)^{2}\right)\left(n \Sigma Y^{2}-(\Sigma Y)^{2}\right)}} \mid
$$

Keterangan:

$\mathrm{r}=$ Nilai koefisien korelasi pearson

$\mathrm{X}=$ Variabel bebas

$\mathrm{Y}=$ Variabel Terikat

Nilai koefisien korelasi (r) terletak antara -1 dan $+1(-1 \leq \mathrm{r} \leq+1)$

1. Jika $r=+1$, terjadi korelasi positif sempurna antara variabel $\mathrm{X}$ dan $\mathrm{Y}$.

2. Jika $r=-1$, terjadi korelasi negatif sempurna antara variabel $\mathrm{X}$ dan $\mathrm{Y}$.

3. Jika $\mathrm{r}=0$, tidak terdapat korelasi antara variabel $\mathrm{X}$ dan $\mathrm{Y}$.

\section{HASIL DAN PEMBAHASAN}

\section{Hasil}

a. Uji Validitas

Pengujian dilakukan dengan membandingkan nilai rhitung dan rtabel untuk degree of freedom $(\mathrm{df})=\mathrm{n}$, dalam hal ini $\mathrm{n}$ adalah jumlah sampel. Pada penelitian ini sampel berjumlah 29. Sehingga dalam penelitian ini besarnya df dapat dihitung sebesar dengan $\mathrm{df}=29$ maka diperoleh rtabel sebesar 0,3673 $(\alpha$ $=5 \%$ ). Hasil perhitungan dapat dilihat pada tabel berikut:

Tabel 1. Hasil Uji Validitas Peran Audit Internal $(\mathrm{X})$

\begin{tabular}{cccc}
\hline Pernyataan & $\begin{array}{c}\text { Corrected Item- } \\
\text { Total } \\
\text { Correlation }\end{array}$ & rtabel & Keterangan \\
\hline Q1 & 0,534 & 0,367 & Valid \\
\hline Q2 & 0,421 & 0,367 & Valid \\
\hline Q3 & 0,529 & 0,367 & Valid \\
\hline Q4 & 0,393 & 0,367 & Valid \\
\hline Q5 & 0,589 & 0,367 & Valid \\
\hline Q6 & 0,500 & 0,367 & Valid \\
\hline Q7 & 0,554 & 0,367 & Valid \\
\hline Q8 & 0,663 & 0,367 & Valid \\
\hline Q9 & 0,555 & 0,367 & Valid \\
\hline Q10 & 0,668 & 0,367 & Valid \\
\hline
\end{tabular}

Sumber: Data olahan 2016

Berdasarkan hasil uji validitas variabel audit internal (X) seperti yang terlihat pada tabel 4.4 bahwa seluruh pernyataan mempunyai rhitung lebih besar dari rtabel yang telah ditetapkan yaitu sebesar 0,367. Jadi dapat disimpulkan 
bahwa 10 item pernyataan tersebut dikatakan memenuhi syarat validitas.

Tabel 2. Hasil Uji Validitas Good Corporate Governance (Y)

\begin{tabular}{|c|c|c|c|}
\hline Pernyataan & $\begin{array}{l}\text { Corrected } \\
\text { Item-Total } \\
\text { Correlation }\end{array}$ & rtabel & Keterangan \\
\hline Q1 & 0,720 & 0,367 & Valid \\
\hline Q2 & 0,674 & 0,367 & Valid \\
\hline Q3 & 0,436 & 0,367 & Valid \\
\hline $\mathrm{Q} 4$ & 0,394 & 0,367 & Valid \\
\hline Q5 & 0,650 & 0,367 & Valid \\
\hline Q6 & 0,715 & 0,367 & Valid \\
\hline Q7 & 0,696 & 0,367 & Valid \\
\hline Q8 & 0,577 & 0,367 & Valid \\
\hline Q9 & 0,377 & 0,367 & Valid \\
\hline Q10 & 0,407 & 0,367 & Valid \\
\hline Q11 & 0,609 & 0,367 & Valid \\
\hline Q12 & 0,628 & 0,367 & Valid \\
\hline Q13 & 0,578 & 0,367 & Valid \\
\hline Q14 & 0,514 & 0,367 & Valid \\
\hline Q15 & 0,535 & 0,367 & Valid \\
\hline Q16 & 0,604 & 0,367 & Valid \\
\hline Q17 & 0,430 & 0,367 & Valid \\
\hline Q18 & 0,656 & 0,367 & Valid \\
\hline Q19 & 0,670 & 0,367 & Valid \\
\hline Q20 & 0,782 & 0,367 & Valid \\
\hline Q21 & 0,457 & 0,367 & Valid \\
\hline Q22 & 0,695 & 0,367 & Valid \\
\hline Q23 & 0,770 & 0,367 & Valid \\
\hline Q24 & 0,816 & 0,367 & Valid \\
\hline Q25 & 0,797 & 0,367 & Valid \\
\hline Q26 & 0,657 & 0,367 & Valid \\
\hline
\end{tabular}

Sumber: Data olahan 2016.

\section{b. Uji Statistik}

Berdasarkan hasil uji validitas variabel good corporate governance $(\mathrm{Y})$ seperti yang terlihat pada tabel 2 bahwa seluruh pernyataan mempunyai rhitung lebih besar dari rtabel yang telah ditetapkan yaitu sebesar 0,367 .

c. Uji Reliabilitas

Tabel 3. Hasil Uji Reliabilitas Variabel Peran Audit Internal (X)
Reliability Statistics

\begin{tabular}{cc}
\hline Cronbach's Alpha & N of Items \\
\hline 0,772 & 10 \\
\hline
\end{tabular}

Sumber: Data olahan 2016

Berdasarkan hasil perhitungan dengan bantuan program SPSS di atas terlihat bahwa dari 29 orang responden untuk item pernyataan yang ada dalam variabel audit internal memiliki tingkat reliabilitas sebesar 0,772. Dapat disimpulkan bahwa sebanyak 10 pernyataan dalam variabel audit internal tersebut adalah reliabel karena $\alpha$ lebih besar daripada 0,60 $(0,772>0,60)$.

Tabel 4. Hasil Uji Reliabilitas Variabel Good Corporate Governance (Y)

Reliability Statistics

\begin{tabular}{cc}
\hline Cronbach's Alpha & N of Items \\
\hline 0,937 & 26 \\
\hline
\end{tabular}

Sumber: Data olahan 2016

Berdasarkan hasil perhitungan dengan bantuan program SPSS di atas terlihat bahwa dari 29 orang responden untuk item pernyataan yang ada dalam variabel good corporate governance memiliki tingkat reliabilitas sebesar 0,937. Dapat disimpulkan bahwa sebanyak 26 pernyataan dalam variabel good corporate governance tersebut adalah reliabel karena $\alpha$ lebih besar daripada $0,60(0,937>0,60)$.

\section{c. Uji Statistik}

Uji statistik pada penelitian ini menggunakan koefisien korelasi pearson, dengan hasil sebagai berikut:

Tabel 5. Peran Audit Internal terhadap Good Corporate Governance

\begin{tabular}{cccc}
\hline & \multicolumn{2}{c}{ Correlations } & \\
\hline & \multicolumn{3}{c}{ VAR00002 } \\
\hline \multirow{2}{*}{ VAR00001 } & Pearson Correlation & 1 &, $726 "$ \\
\cline { 2 - 4 } & Sig. (2-tailed) & &, 000 \\
\cline { 2 - 4 } & $\mathrm{N}$ & 29 & 29 \\
\hline
\end{tabular}




\begin{tabular}{cccc}
\hline \multirow{2}{*}{ VAR00002 } & Pearson Correlation &, $726 ”$ & 1 \\
\cline { 2 - 4 } & Sig. (2-tailed) &, 000 & 29 \\
\cline { 2 - 4 } & $\mathrm{N}$ & 29 & 29 \\
\hline
\end{tabular}

Dari pengujian tersebut juga dapat diketahui bahwa audit internal berhubungan positif terhadap good corporate governance dengan besar korelasi auditor internal terhadap good corporate governance adalah 0,726 atau $72,6 \%$. Dengan demikian tinggi rendahnya good corporate governance dipengaruhi oleh auditor internal sebesar $72,6 \%$ sedangkan sisanya $27,4 \%$ dijelaskan faktor lain diluar model.

\section{Pembahasan}

Berdasarkan pengujian korelasi pearson menyatakan bahwa independensi berhubungan terhadap good corporate governance yang menunjukkan nilai signifikan sebesar 0,001 < 0,05 . Kemampuan profesional berhubungan terhadap good corporate governance yang menunjukkan nilai signifikan sebesar 0,001 < 0,05 . Lingkup pekerjaan berhubungan terhadap good corporate governance yang menunjukkan nilai signifikan sebesar $0,001<0,05$. Pelaksanaan kegiatan pemeriksaan tidak berhubungan terhadap good corporate governance yang menunjukkan nilai signifikan sebesar $0,100>0,05$.

Berdasarkan hasil uji korelasi pearson dalam pengujian hipotesis, untuk variabel $\mathrm{X}$ (audit internal) dan Y (good corporate governance) menunjukkan hasil nilai signifikan sebesar $0,000<0,05$ berarti Ho ditolak, maka $\mathrm{H} 1$ diterima, berarti "Audit internal mempunyai peranan yang memadai dalam mendukung good corporate governance yang efektif pada PT. Pelabuhan Indonesia IV (Persero)". Dari pengujian tersebut juga dapat diketahui bahwa audit internal berhubungan positif terhadap good corporate governance dengan besar korelasi auditor internal terhadap good corporate governance adalah 0,726 atau $72,6 \%$.

Dengan demikian tinggi rendahnya good corporate governance dipengaruhi oleh auditor internal sebesar $72,6 \%$ sedangkan sisanya 27,4\% dijelaskan faktor lain diluar model. Hasil penelitian ini juga menunjukkan kesamaan dengan penelitian yang dilakukan oleh Nurmalia (2016) yang melakukan penelitian mengenai peran audit internal dalam mewujudkan Good Corporate Governance (Studi pada Perusahaan Daerah Air Minum (PDAM) Kabupaten Blitar) yang menunjukkan bahwa berdasarkan korelasi model pearson peran audit internal dalam perwujudan good corporarte governance menunjukkan nilai signifikan $0.038<0,05$ audit internal berpengaruh terhadap good corporate governance.

\section{KESIMPULAN DAN SARAN}

\section{Kesimpulan}

Berdasarkan hasil analisis data dan pengujian hipotesis yang telah diuraikan pada bab sebelumnya kesimpulan yang dapat diambil dalam penelitian ini adalah audit internal mempunyai peranan yang memadai dalam mendukung good corporate governance pada PT. Pelabuhan Indonesia IV (Persero) Makassar sekaligus meunujukkan kesamaan hasil penelitian oleh Nurmalia (2016) yang melakukan penelitian mengenai peran audit internal dalam mewujudkan Good Corporate Governance (Studi pada Perusahaan Daerah Air Minum (PDAM) Kabupaten Blitar) yang menunjukkan bahwa berdasarkan korelasi model pearson peran audit internal dalam perwujudan good corporarte governance menunjukkan nilai signifikan $0.038<0,05$ audit internal berpengaruh terhadap good corporate governance.

\section{Saran}

Auditor diharapkan selalu menjaga profesionalisme dalam melaksanakan pekerjaanya agar dari independensi auditor bisa bersikap objektif, independen, dan profesional dalam melakukan audit. Sedangkan dari segi kemampuan profesional para auditor harus 
mengembangkan kemampuan tekniknya untuk menunjang pelaksanaan dan menguasai berbagi ilmu pengetahuan yang seharusnya dimiliki oleh seorang auditor. PT. Pelabuhan Indonesia IV (Persero) selalu mengikutsertakan para auditornya dalam kursus-kursus untuk mendapatkan serifikat seperti QIA (Qualified Internal Auditor), CPA (Cortified Public Accountant), CIA (Certified Internal Auditor) dan sertifikat lainnya yang dapat meningkatkan kualitas auditor internal.

\section{REFERENSI}

Agoes, S. (2012). Auditing Petunjuk Praktis Pemeriksaan Akuntan oleh Akuntan Publik, Jilid 1, Edisi keempat. Jakarta: Salemba Empat.

Andayani, W. (2008). Audit Internal (edisi 1). Yogyakarta: BPFE-YOGYAKARTA.

Halim, A. (2015). Auditing Dasar-dasar Audit Laporan Keuangan, Jilid 1, Edisi kelima. Yogyakarta: UPP STIM YKPN.

Hamdani. (2016). Good Corporate Governance Tinjauan Etika dalam Praktik Bisnis. Jakarta: Mitra Wacana Media.

Hery. (2016). Auditing dan Asurans Pemeriksaan Akuntansi Berbasis Standar Audit Internasional. (Adipramono, Ed.). Jakarta: PT Grasindo.

Hermansyah, A. (2010). Pengaruh Auditor Eksternal dan Internal Auditor pada Pelaksanaan Good Corporate Governance. Jurnal Trikonomika. Volume 9, No. 1, Juni 2010, Hal. 37-47. ISSN 1411-514X (2 Februari 2017)

Kusumawati, N. A. (2016). Peran Audit Internal dalam mewujudakn Good Corporate Governance. Jurnal Riset Mahasiswa
$(J R M x)$. ISSN: 2337-56xx. Volume: $\mathrm{xx}$, Nomor: $\mathrm{xx}$

Maylia Pramono Sari, R. (2012). Peran Audit Internal Dalam Upaya Mewujudkan Good Corporate Governance (GCG) Pada Badan Layanan Umum (BLU) Di Indonesia. Jurnal Simposium Nasional Akuntansi. (2 Februari 2017)

Nugroho, D. P. (2012). Pelaksanaan Audit Internal Dalam Mewujudkan Good Corporate Governance Pada Sektor Publik. (6 Februari 2017)

Putra, V. D. cahaya. (2014). Peran Audit Internal dalam Upaya Mewujudakan Good Corporate Governance (Studi pada Perusahaan Daerah Air Minum (PDAM) Tirtawening Kota Bandung. (21 Januari 2017)

Rismawati, Muh. Yusuf Q, A. R. asriani. (2015). Pengaruh Internal Audit Terhadap Penerapan Good Corporate Governance Pada PT. FIF Cabang Palopo. Jurnal Akuntansi.Vol. 02 No. 01. (24 Januari 2017).

Saptapradipta, P. (2013). Pengaruh Audit Internal dan Pengendalian Internal Terhadap Peaksanaan Good Governance (Studi pada Badan Layanan Umum Universitas Brawijaya malang).(2 Februari 2017)

Siti Kurnia Rahayu, W. (2014). Pengaruh Audit Internal dan Pelaksanaan Pengendalian Internal Terhadap Pelaksanaan Good Corporate Governance (Survei pada Bank BUMN dikota Bandung). (2 Februari 2017)

Soetjipta, F. H. (2013). Peranan audit Intern Dalam Penerapan Good Corporate Governance yang Efektif (Studi Kasus PT. XYZ, Bandung). Akurat Jurnal 
Ilmiah Akuntansi. ISSN: 2086-4159.

Nomor 10 Tahun ke-3 Bulan Mei-

Agustus 2013 (24 Januari 2017)

Tunggal, A. W. (2014). Ringkasan, Soal, dan Solusi Internal Audit. Jakarta: Harvarindo.

Tunggal, A. W. (2012). Seluk-Beluk Internal Auditing. Jakarta: Harvarindo.

Tunggal, A. widjaja. (2016). Teknik-Teknik Audit Internal. Jakarta: Harvarindo.

Wardoyo, T. S. (2010). Peranan Auditor Internal dalam Menunjang Pelaksanaan Good Corporate Governance. Akurat Jurnal Ilmiah Akuntansi. (8 Februari 2017)

William F. Messier, Steven M. Glover, D. F. P. (2014). Jasa Audit dan Assurance Pendekatan Sistematis Edisi 8. Jakarta: Salemba Empat.

Zarkasyi, W. (2008). Good Corporate Governance Pada Badan Usaha Manufaktur, Perbankan, dan Lembaga Keuangan Lainnya. Bandung: Alfabets. 